\title{
White-noise-like distribution of the oceanic copepod Neocalanus cristatus in the subarctic North Pacific
}

\author{
Atsushi Tsuda ${ }^{1}$, Hiroya Sugisaki ${ }^{1, *}$, Takashi Ishimaru ${ }^{2}$, Toshiro Saino ${ }^{1}$, Tosiya Sato ${ }^{3}$ \\ ${ }^{1}$ Ocean Research Institute, University of Tokyo, 15-1 Minamidai 1, Nakano, Tokyo 164, Japan \\ ${ }^{2}$ Department of Aquatic Bioscience, Tokyo University of Fisheries, 5-7 Kounan 4, Shinagawa, Tokyo 108, Japan \\ ${ }^{3}$ Institute of Statistical Mathematics, Minami-Azabu 4-6-7, Minato, Tokyo 106, Japan
}

\begin{abstract}
Continuous estimates of Neocalanus cristatus abundance were obtained with an electric particle counter along a cruise track in the subarctic western North Pacific in spring. In meso- to megascale observations, with sampling interval $510 \mathrm{~m}$ and coverage $2519 \mathrm{~km}$, the number of patches decreased exponentially both with increasing patch size and with density of the copepods in the patch. The maximum patch size and density were $6.6 \mathrm{~km}$ and 1230 ind. $\mathrm{m}^{-3}$, respectively. In micro-scale observations, with sampling interval 10 to $30 \mathrm{~m}$, the number of patches also decreased exponentially with patch size and density. Spectral analysis of temperature, salinity, in vivo chlorophyll fluorescense and copepod abundance showed that the copepod did not have the characteristic patch-length or wavenumber dependencies observed in the other parameters. These white-noise-like spectra, together with the general observations on micro- to mega-scales, suggested that $N$. cristatus had patches in all length scales from at least $10 \mathrm{~m}$ to $50 \mathrm{~km}$, and that patches of a given order were constituted by the gathering of smaller-scale patches.
\end{abstract}

\section{INTRODUCTION}

Heterogeneity of zooplankton distribution such as patchiness or schooling is a long-recognized phenomenon (e.g. Hardy 1936). Development of continuous plankton samplers has substantially contributed to studies of patchiness characteristics such as size, density of organisms and community structure (Longhurst et al. 1966, Wiebe 1970, Fasham et al. 1974, Mullin \& Williams 1983). Patchiness of plankton is important for survival of pelagic fishes (LeBrasseur et al. 1969, Lasker 1975) and planktivorous manine mammals (Kawamura 1982), and for studies on zooplankton population dynamics and community structures (Wiebe 1970). Recently, the importance of patchiness has been stressed in relation to zooplankton behavior (Hamner 1988).

Size and animal density of patches have been the subjects of many studies. Usually patches have been

\footnotetext{
- Present address: Tohoku National Fisheries Research Institute, 27-5 Shinhama 3, Shiogama, Miyagi 985, Japan
}

classified as a cluster of animals having a density several times higher than average or background density. An extremely high density $\left(10^{7}\right.$ ind. $\left.\mathrm{m}^{-3}\right)$ was reported for diapausing Calanus pacificus (Alldredge et al. 1984). For relatively large copepods such as Neocalanus spp., 100 to 1000 ind. $\mathrm{m}^{-3}$ were reported as patches (Barraclough et al. 1969, Kawamura \& Hirano 1985). Size of patches also varies among zooplankton species and among sampling tools, e.g. from several tens of $\mathrm{cm}$ for visually oriented copepods in coral reefs (Hamner \& Carleton 1979) to several tens of $\mathrm{km}$ for oceanic copepods (Cushing \& Tungate 1963, Paffenhöfer et al. 1981). Mackas \& Boyd (1979) used spectral analysis for continuous estimates of copepod abundance in the horizontal plane to investigate patch scale. They showed that copepods did not have a characteristic patch length, and have a weaker wavenumber dependence than phytoplankton.

In this study, we carried out continuous estimates of an abundant and large boreal copepod, Neocalanus cristatus (Krøyer), using a system like that of Mackas \& 


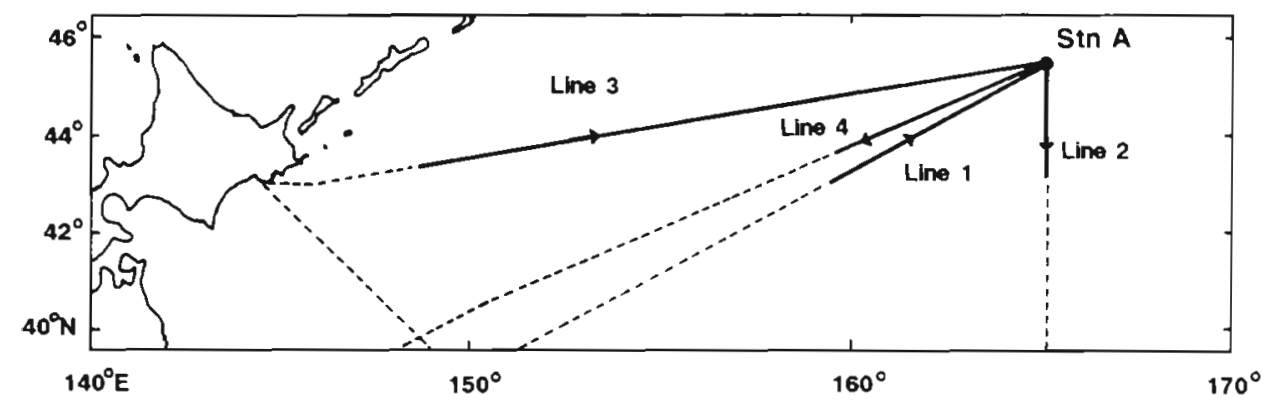

Fig. 1. Cruise track and location of micro-scale sampling station in the North Pacific. Thick lines indicate area used for analysis in this study. Arrows indicate ship direction. Sampling times: Line 1, 07:52 h on May 12 to $00: 07 \mathrm{~h}$ on May 13; Line 2, 14:42 to 22:15 h on May 16; Line 3, 02:21 h on May 31 to 13:36 h on June 2; Line 4, 13:43 h on June 4 to 04:35 h on June 5; Stn A, 00:08 h on May 13 to $14: 41$ h on May 15 and 13:36 h on June 2 to $13: 43$ h on June 4

P-03 electronic planktoncounting and sizing system, a Danfoss MAG1100/1000 electromagnetic flow meter and 5 Bran Lubbe AAll Auto Analyzer channels. We did not analyze the data obtained by the DO meter or the Auto Analyzer in this study. Seawater was pumped up to the system from the ship's bottom (about $5 \mathrm{~m}$ depth). Flow rate of seawater through the system was maintained at $17.0 \pm 0.3 \mathrm{l}$ min $^{-1}$. Data from each sen-

Boyd (1979) to deduce patch characteristics and the relationships between copepod distribution and environmental parameters. We also examined the spatial scale and method of sampling suitable for quantitative estimation of the copepod.

\section{MATERIALS AND METHODS}

Observations were done at Stn $A$ and along 4 transect lines during the RV 'Hakuho-Maru' cruise KH-913, from 10 May to 11 June 1991 (Fig. 1). A thermal front was located around $43^{\circ} \mathrm{N}$ in all the transect lines. Homogeneous subarctic water was selected for the analysis of Neocalanus cristatus, although they were also distributed abundantly in the frontal area. Therefore, the area studied was located between $43^{\circ}$ and $45^{\circ} \mathrm{N}$ with water temperature of $<5.4^{\circ} \mathrm{C}$. The area was characterized by low chlorophyll a $\left(0.7 \mu \mathrm{g} \mathrm{l}^{-1}\right)$ and high nitrate concentration $(16 \mu \mathrm{M})$ in the surface layer at $\operatorname{Stn} \mathrm{A}$ (Koike in press).

We carried out 2 series of observations. One consisted of meso/mega-scale observations performed while cruising at a ship speed of ca $30.6 \mathrm{~km} \mathrm{~h}^{-1}$ along the tracks indicated by thick lines in Fig. 1. The second consisted of micro-scale observations to examine the fine structure of the patches. Periods with low ship speed $\left(<1.85 \mathrm{~km} \mathrm{~h}^{-1}\right)$ were selected from the data at Stn A.

Continuous recording of environmental parameters and zooplankton abundance was done with an AMEMBO (Water Strider AutoMated Environmental Monitor for Biological Oceanography). The AMEMBO was of a design similar to the system of Boyd (1973) with some modifications. The system consists of a bubble trap, a Seabird SBE-21 thermosalinograph, a Turner Design 10- $\mathrm{R}$ in vivo fluorometer, a Danfoss TDO/EMCO dissolved oxygen (DO) meter, a Honchigo sor were recorded together with navigation data on a floppy disk. For the plankton counting and sizing system, integrated data in $1 \mathrm{~min}$ were recorded. The navigation data were obtained from a Magnavox Type 5000 hybrid navigation system through a local area network.

Particles larger than $0.35 \mathrm{~mm}$ estimated spherical diameter which passed through the particle counter were enumerated in 10 size categories. The largest size category, ranging from $0.78 \mathrm{~mm}$ to the orifice diameter $(3 \mathrm{~mm})$, was used for the analysis. Neocalanus cristatus copepodite stage $\mathrm{V}$ and Eucalanus bungii adult females were the only dominant organisms in this size category, which was revealed by microscopic counts and sizings of zooplankton collected by vertical tows of the plankton net at Stn A (Tsuda \& Sugisaki unpubl.). Larger animals, such as euphausiids, were mostly trapped by a prefilter ( $3 \mathrm{~mm}$ mesh opening). Because $E$. bungii was distributed deeper than $40 \mathrm{~m}$

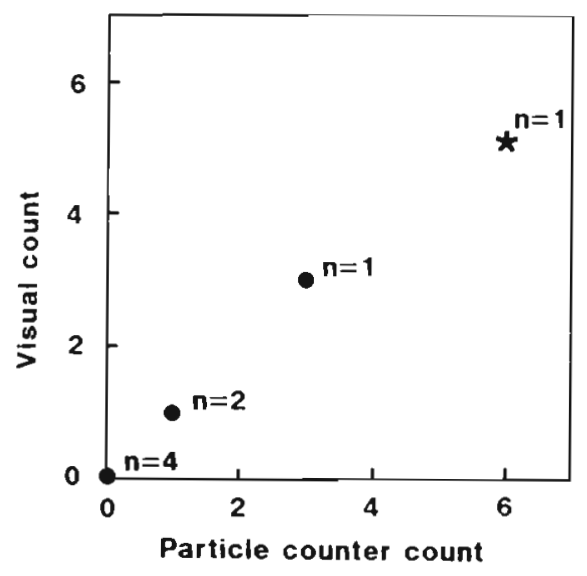

Fig. 2. Relation between counts from the AMEMBO particle counter and visual counts of Neocalanus cristatus. $\star$ : A fragment of euphausiid was counted by the particle counter 
throughout the day (Tsuda \& Sugisaki unpubl.), the particles in this size range were considered to be $N$. cristatus copepodite V. Moreover, direct visual counts of copepods taken from the system outlet coincided with counts from the particle counter (Fig. 2).

The high-density areas ( $\geq 3$ counts $\mathrm{min}^{-1}$ ) among the 2800 data along the 4 transect lines were regarded as copepod patches. Three counts $\mathrm{min}^{-1}$ are equivalent ca 173 ind. $\mathrm{m}^{-3}$, and present 5 times the average density at night or the average $+1.5 \mathrm{SD}$. This threshold is comparable to those of relatively large copepod species in other studies (Barraclough et al. 1969, Kawamura \& Hirano 1985). Furthermore, the median value was 0 counts $\min ^{-1}$ in the 2 transects and 1 in the other transect; accordingly, our threshold was higher than that of Wiebe (1970). Patch lengths were defined as the number of consecutive sampling intervals ( $1 \mathrm{~min}$ or $510 \mathrm{~m}$ ) with continuous high density. We did not calculate patch diameter because there was no information on patch shape. In this procedure, small-scale
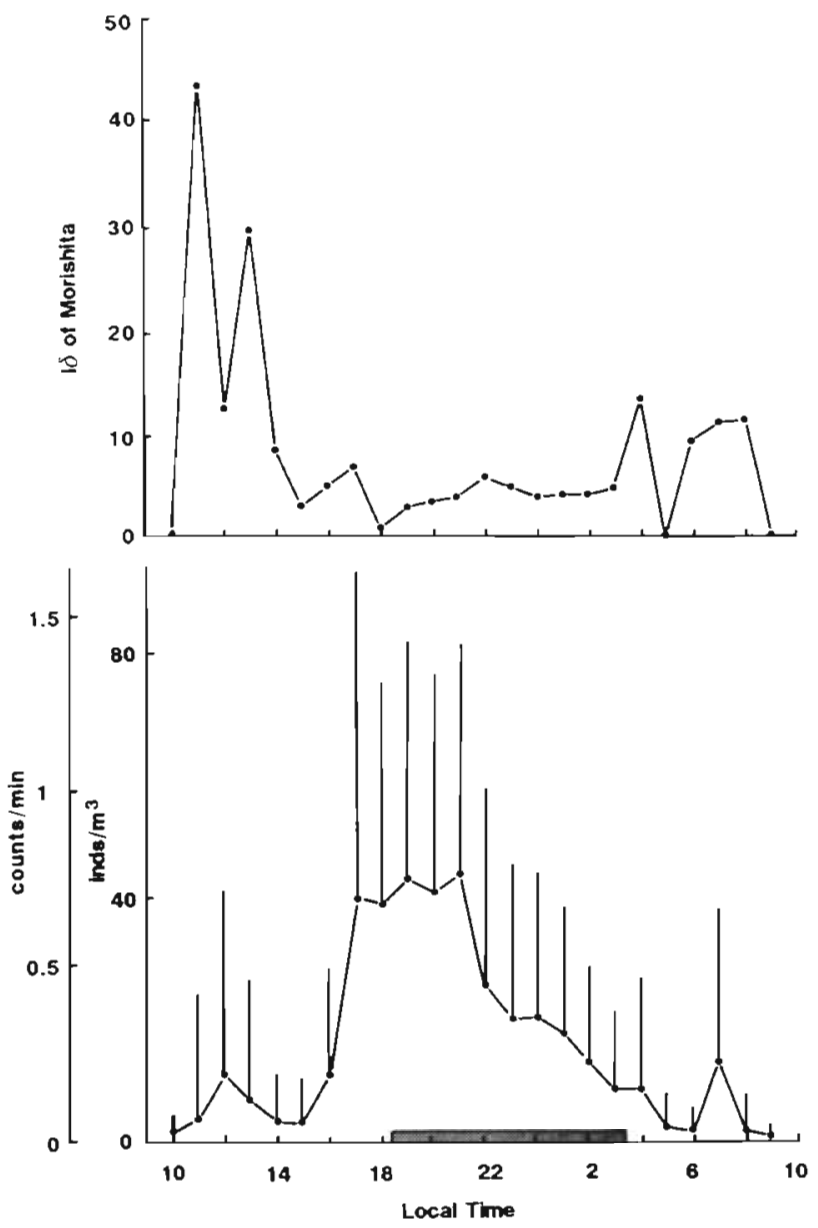

Fig. 3. I 8 of Morishita (1959) and mean counts of Neocalanus cristatus as a function of time of day. Shaded area represents nighttime. Vertical lines indicate $0.5 \mathrm{SD}$ patches (mean density $<173$ ind. $\mathrm{m}^{-3}$ along $510 \mathrm{~m}$ of track) were neglected in the meso/mega-scale observations.

Spectral analysis by FFT (Fast Fourier Transformation) was made for the estimation of scale dependencies of fluctuation in sigma-t, chlorophyll fluorescence and copepod abundance.

\section{RESULTS}

\section{Meso/mega-scale observations}

The density of the copepod was frequently high from before dusk to midnight (Fig. 3). Abundance decreased from midnight until dawn and stayed low during daylight. Discrete-depth net sampling showed that Neocalanus cristatus was distributed in the 0 to $40 \mathrm{~m}$ layer throughout a day at Stn A (Tsuda \& Sugisaki unpubl.). Therefore, circadian occurrence of the copepod indicated small-scale diel vertical migration. Firstly, Morishita's Index I $\delta$ (Morishita 1959) was calculated to test the departure from randomness in the distribution. The formula is $I \delta=n x_{\mathrm{i}}\left(x_{\mathrm{i}}-1\right) / N(N-1)$, where $n$ is the number of samples, $x_{1}$ is the number of copepods in the $i$ th sample, and $N$ is the total number of copepods. The copepod showed a contagious distribution throughout the day $(I \delta>1)$, and $I \delta$ was high during daylight (Fig. 3). These high values, however, could be caused by a statistical problem related to few individuals per sample (Cassie 1963).

The total number of patches observed was 150 along $2519 \mathrm{~km}$ of cruise track. Size distribution of the patches is shown in Fig. 4. The maximum patch length observed was $6.6 \mathrm{~km}$ (13 min); however, $75 \%$ of patches were observed within single, isolated units of observation (1 $\mathrm{min})$. The maximum density recorded was 1230 ind. $\mathrm{m}^{-3}$, although patches with lower density dominated (Fig. 5).

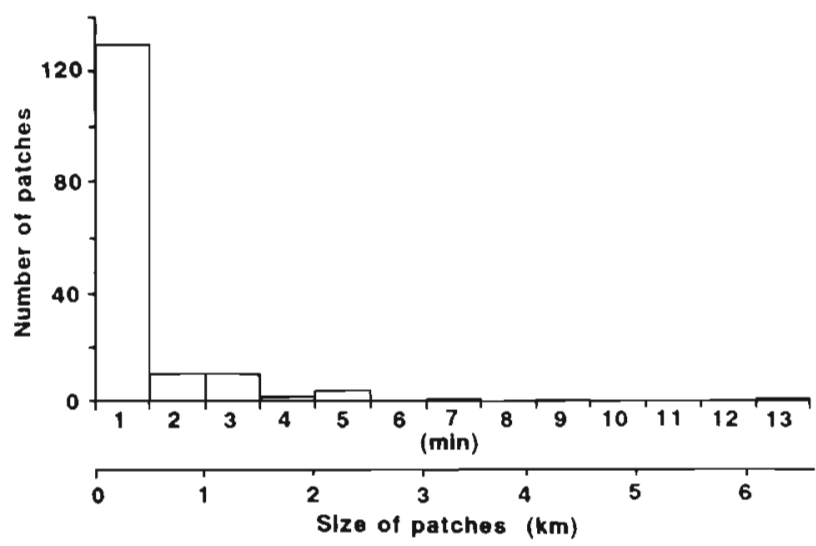

Fig. 4. Size distribution of copepod patches in the meso/ mega-scale observations 


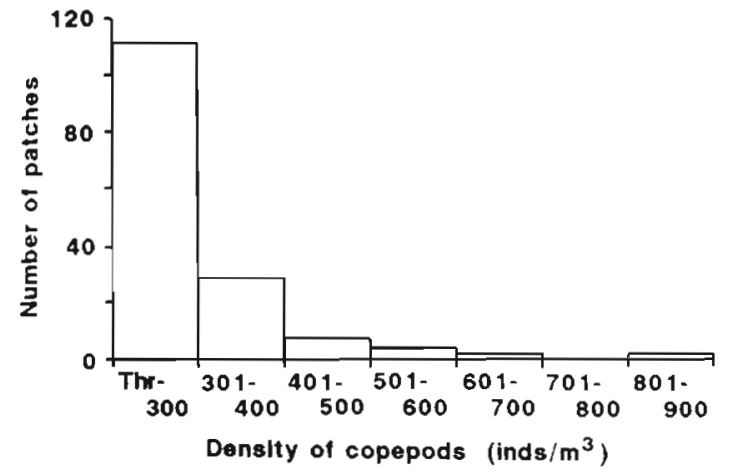

Fig. 5. Distribution of copepod density in patches during the meso/mega-scale observation. Thr: threshold density of patch in this study ( 3 counts min $^{-1}$, ca 173 ind. $\mathrm{m}^{-3}$ )

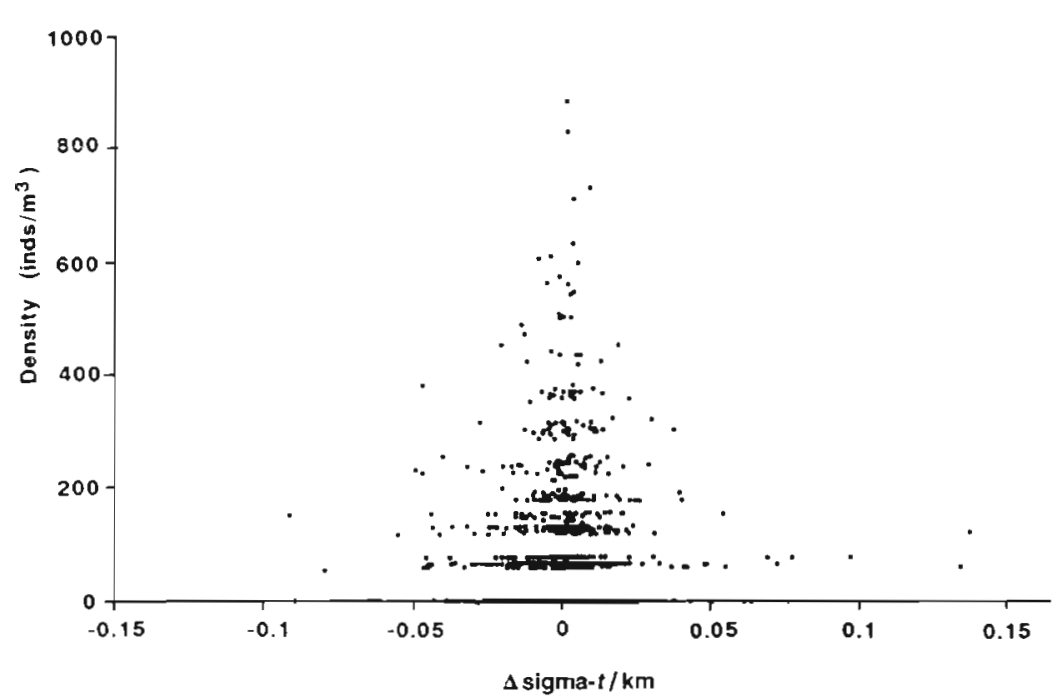

Fig. 6. Relation between sigma-t gradient and copepod abundance in the meso/mega-scale observation during night. Means of positive values increase toward the east

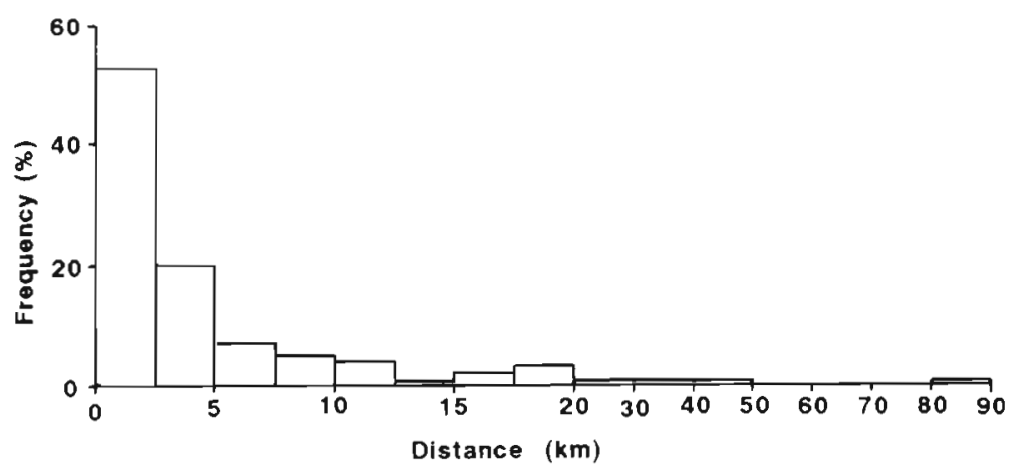

Fig. 7. Distribution of inter-patch distance during the meso/mega-scale observation. Data used only from night periods

We could not find any correlations between copepod patch and environmental parameters (temperature, salinity and chlorophyll fluorescence). Careful observa- tion of patch occurrence revealed that high copepod abundance occurred at locations with horizontally stable salinity. This tendency was more clearly shown in the relation with the density gradient (Fig. 6). We examined whether copepod densities were high around low sigma-t gradients. We tested the null hypothesis that the mean copepod density in each interval of sigma-t gradient was constant, assuming the alternative that the logarithm of density was quadratic on sigma-t gradient. Derivation of the test is given in the Appendix. High abundance of the copepod at locations of low density gradient was not significantly more frequent than predicted by the null hypothesis.

Inter-patch distance (consecutive sampling intervals having lower copepod density than the threshold) at night was $5.8 \mathrm{~km}$ on average. Although there were cases with no patches for several tens of $\mathrm{km}$, shorter intervals were more frequent (Fig. 7). Thus, copepod patches were distributed unevenly, in other words patchily. We performed spectral analysis to examine scale dependence of the copepod distribution. A set of representative power spectra is shown in Fig. 8. There were no significant differences in the spectra among the transect lines. The variance of sigma-t decreased linearly with increasing wave-number (decreasing wavelength) in a log-log plot. The slope was close to the theoretical value $-5 / 3$ (Platt \& Denman 1975). Chlorophyll fluorescence also had a similar spectrum. In contrast, the copepod spectra were quite different from the others (Fig. 9). The variance decreased from $500 \mathrm{~km}$ to $50 \mathrm{~km}$, and white-noise-like spectra were observed at shorter wavelengths.

\section{Micro-scale observations}

Patches of 10 to $20 \mathrm{~m}$ length were most frequently observed in the microscale observations (Fig. 10A), however this depends partly on ship speed frequency. When we take the unit time of observation ( $1 \mathrm{~min}$ ) on the $x$-axis, the size distribution obtained was quite similar in shape to that of the meso/megascale observations (Fig. 10B). The maximum length observed was $136 \mathrm{~m}$, which was smaller than the threshold of the meso/mega-scale observations. Density distribution of the copepod in the patches was also similar to the meso/mega-scale 


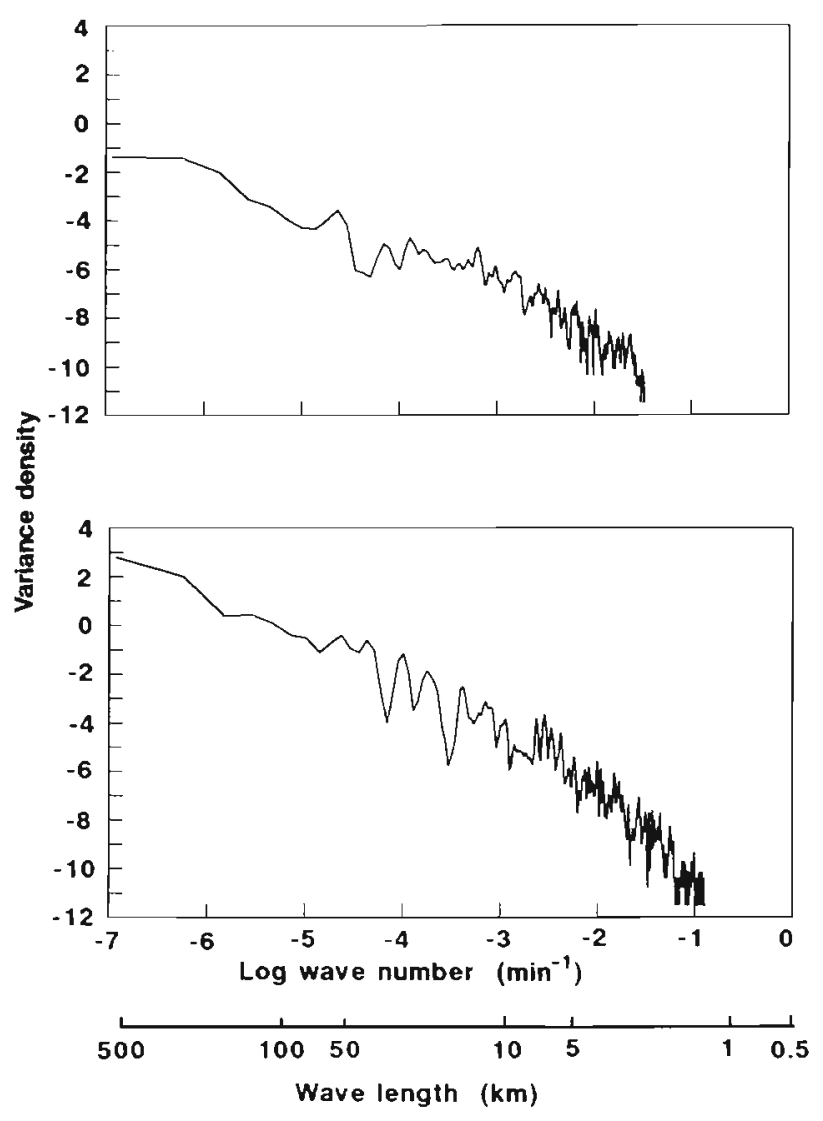

Fig. 8. Power spectra calculated for sigma-t (upper) and chlorophyll fluorescence (lower) on Transect line 4

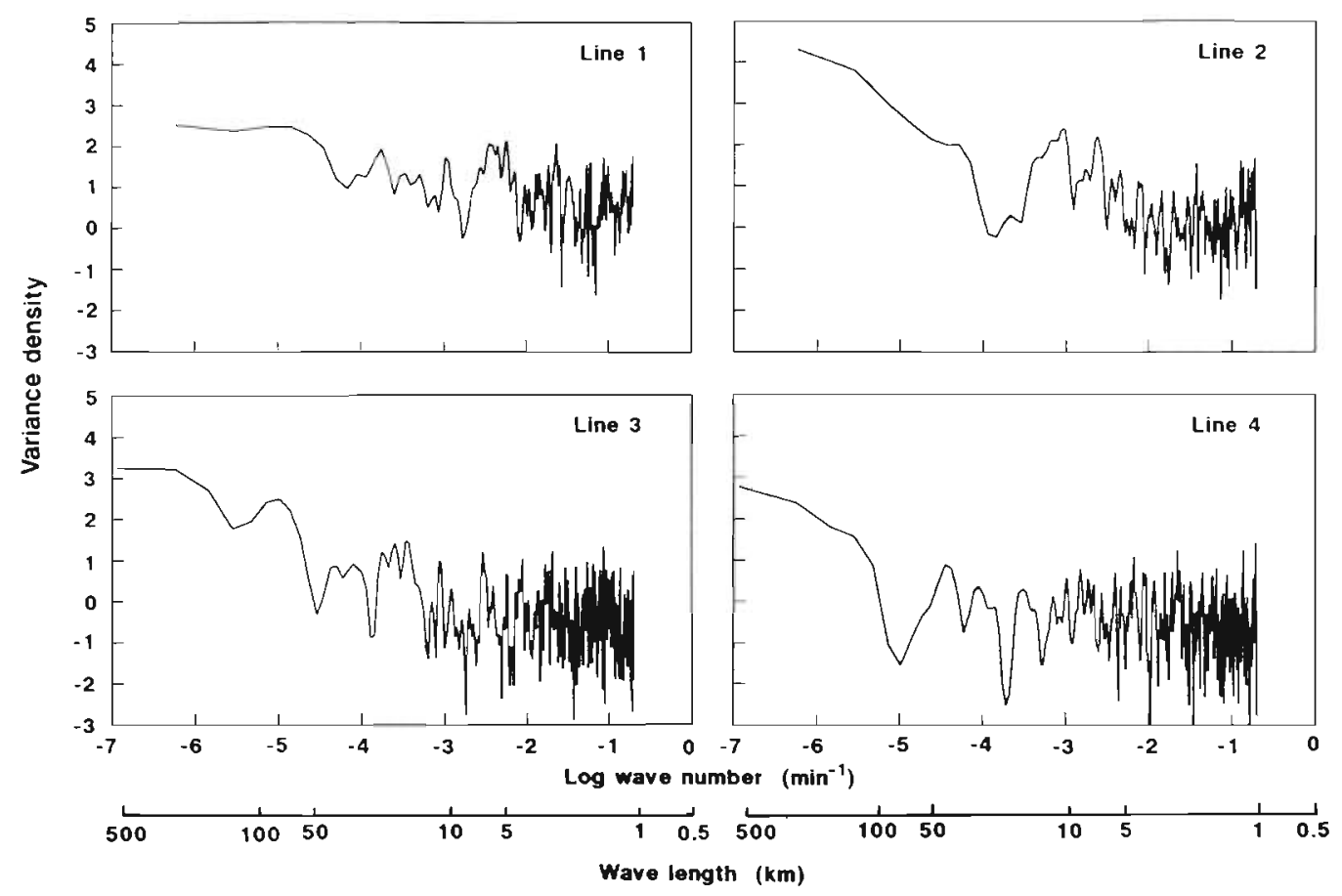

Fig. 9. Neocalanus cristatus. Power spectra calculated for 4 transect lines. Data used only from night periods 


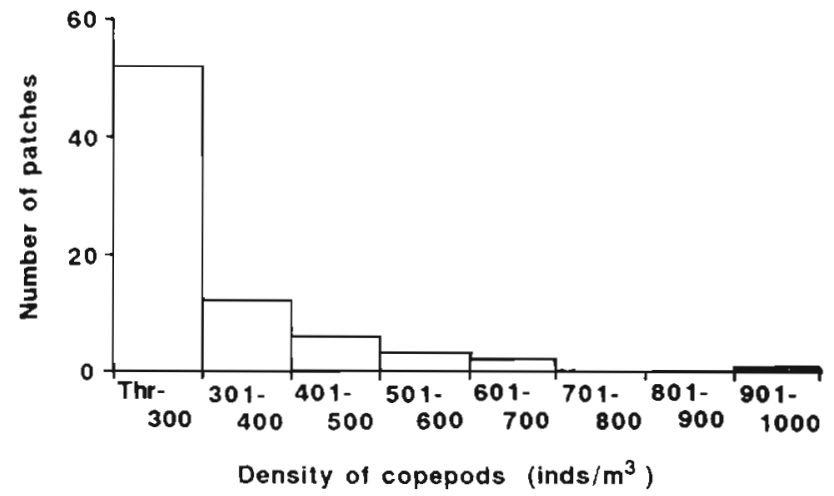

Fig. 11. Distribution of copepod density in the patch during the micro-scale observation. Thr: threshold density of patch in this sludy $\left(3\right.$ counts $\mathrm{min}^{-1}$, ca 173 ind. $\mathrm{m}^{-3}$ )

density distribution (Fig. 11). The number of patches decreased exponentially with increase in copepod density. The range of copepod density did not differ from that of the meso/mega scale.

\section{DISCUSSION}

Neocalanus cristatus was distributed heterogeneously or patchily. Our sampling was not adequate for assessing the daytime distribution because the copepod is mainly distributed below $20 \mathrm{~m}$ depth in this region (Barraclough et al. 1969). However, Barraclough et al. mentioned that copepod distribution during the day, examined with an echo sounder, was intermittent or patchy. Therefore, the distribution of $N$. cristatus was considered to remain patchy throughout the day, in spite of the diel vertical migration. We observed 150 clusters of high abundance which ex-

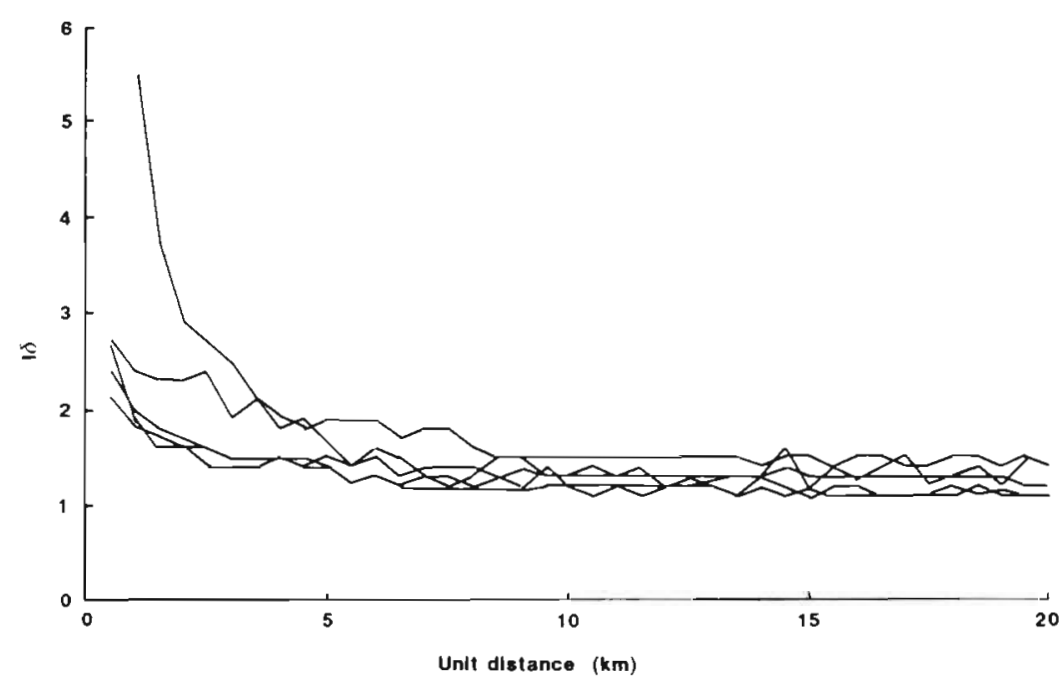

Fig. 12. I $\delta$ of Morishita (1959) as a function of the unit distance of the observation for 4 transect lines. Data used only from night periods ceeded the average (background) 5-fold during the $2519 \mathrm{~km}$ cruise track. The maximum abundance observed reached 25 times the average.

Copepod patch sizes which have been reported range from several tens of $\mathrm{cm}$ to several tens of $\mathrm{km}$, as mentioned in the 'Introduction'. Mackas \& Boyd (1979) showed that zooplankton in the North Sea, which were composed mainly of several species of copepod, had no characteristic patch-length and weaker wave-number dependence than phytoplankton, using a similar particle counter to our study. Similar results were reported in other areas (Smith et al. 1976, Greenblatt et al. 1982). We examined the distribution of a single species and obtained a similar result to Mackas \& Boyd (1979). More importantly, the copepod had little wave-number dependence (being instead white-noise-like) between 1 and $50 \mathrm{~km}$ scales. In the micro-scale observations, patches of about $10 \mathrm{~m}$ size dominated; therefore, the white-noise-like distribution should prevail from $50 \mathrm{~km}$ to at least the $10 \mathrm{~m}$ scale. In conclusion, the copepod had every patch size or distribution bias between $10 \mathrm{~m}$ and $50 \mathrm{~km}$, and smaller patches were more frequent. In other words, the patches of a given order are formed by gatherings of patches of a smaller order, analogous to a hierarchy of eddies in fully developed turbulence (Richardson 1922). If this pattern of distribution is common for other copepod species, the observed patch size may be affected by the scale of the observations.

White-noise-like distribution of Neocalanus cristatus cannot be explained by the balance between growth and turbulent diffusion which has been taken to explain phytoplankton distribution (Platt \& Denman 1975, Mackas et al. 1985). It is more likely that behavioral and physiological adaptative processes dominate over reproductive population growth in the formation of small-scale aggregations (Stavn 1971, George \& Edwards 1976). In this study, patches with high density only occurred at places with horizontally stable sigma-t (Fig, 6), although that relationship was not significant statistically. Moreover, it is hard to believe that copepod patches on the scale of several tens of $\mathrm{km}$ were maintained only by behavioral processes. Therefore, physical and behavioral interaction is the most plausible mechanism causing a white-noise-like distribution of the copepod

Quantitative sampling and knowledge of heterogeneous distributions are fundamental for investigations of population dynamics, community structures and energy/material flux of 
zooplankton in marine ecosystems. We showed that the copepod Neocalanus cristatus was distributed very heterogeneously. What type of quantitative sampling is most reliable? Theoretically, the pattern of distribution changes from a contagious distribution to a uniform one with increase in the unit distance of the observation. The data set on $N$. cristatus was used for this analysis (Fig. 12). IS decreased with increasing unit distance of the observation and became constant (ca 1.5) between 5 and $10 \mathrm{~km}$, although there were some differences among the transect lines. I $\delta$ did not decrease to less than 1.0 (indicating uniform distribution) because there were longer wavelength fluctuations. Consequently, sampling over at least $5 \mathrm{~km}$ is recommended for quantitative estimation of this copepod. This standard actually seems impossible for ordinary net samplings; however, continuous recordings with a particle counter or high-frequency echo sounder (Barraclough et al. 1969) should be suitable for this purpose.

Acknowledgements. We thank Drs $M$. Terazaki and $\mathrm{K}$. Kawaguchi for their helpful suggestions throughout this work. We also grateful to Dr C. B. Miller for his critical reading and correcting of the English manuscript. Thanks are extended to Dr S. Kimura for providing us with the computer program of spectral analysis and valuable discussion. This study would not have been possible without the assistance and cooperation of the captain, officers and crew of the RV 'Hakuho-Maru'

\section{Appendix}

\section{The test for homogeneity of mean densities}

We set a 0.01 interval for sigma- $t$ gradient presented in Fig. 6 from -0.05 to +0.05 . Let $m_{i}$ and $y_{j}$ be the number of total observations and the sum of the positive counts, respectively, in the $i$ th interval for $i=1, \ldots, 10$. Each observation in the $i$ th interval is assumed to have an independent Poisson distribution with mean $\mu_{1}$. In order to examine whether copepod densities are high around zero sigma- $t$ gradient, we considered a quadratic Poisson regression model (McCullagh \& Nelder 1989) that $\log \mu_{i}=\beta_{0}+\beta_{1} \mathrm{~d}_{i}^{2}$, where $\beta_{1}<0$ and $d_{i}$ is the median sigma-t gradient in the $i$ th interval. The null hypothesis to be tested is that $\log \mu_{1}$ is constant through all the intervals against the quadratic change alternative

The constant $\mu_{1}$ is equivalent to the assumption that $\beta_{1}=$ 0 in the above Poisson regression model. When testing that hypothesis, the efficient score test based on the likelihood approach (Cox \& Hinkley 1974) is derived by

$$
X^{2}=\frac{\mathrm{m}_{+}^{2}}{y_{+}} \frac{\left(\sum_{i} y_{i} d_{i}^{2}-\frac{y_{+}}{m_{+}} \sum m_{i} d_{i}^{2}\right)^{2}}{m_{+} \sum_{i} m_{i} d_{i}^{4}-\left(\sum_{i} m_{i} d_{i}^{2}\right)^{2}},
$$

where $\mathrm{m}_{+}=\sum_{i} \mathrm{~m}$, and $\mathrm{y}_{+}=\sum_{i} \mathrm{y}_{i}($ for $i=1, \ldots, 10)$, which has an approximately chi-square distribution with one degree of freedom.

The result of analyzing the data in Fig. 6 is shown in Table 1 . The mean copepod densities are almost constant and the calculated p-value is 0.695 .
Table 1. Mean densities for each sigma-t gradient interval

\begin{tabular}{|cc|}
\hline Sigma-t gradient & Mean densities \\
\hline-0.05 to -0.04 & 1.07 \\
-0.04 to -0.03 & 0.68 \\
-0.03 to -0.02 & 0.58 \\
-0.02 to -0.01 & 0.89 \\
-0.01 to 0.0 & 0,85 \\
0.0 to +0.01 & 1.07 \\
+0.01 to +0.02 & 0.89 \\
+0.02 to +0.03 & 0.91 \\
+0.03 to +0.04 & 0.95 \\
+0.04 to +0.05 & 1.56 \\
Total & 0.93 \\
Chi-square $=0.153, p=0.695$ & \\
\hline
\end{tabular}

\section{LITERATURE CITED}

Alldredge, A. L., Robinson, B. H., Fleminger, A., Torres, J. T., King, M. J., Hamner, W. M. (1984). Direct sampling and in situ observation of a persistent copepod aggregation in the mesopelagic zone of the Santa Barbara Basin. Mar. Biol. 80: 75-81

Barraclough, W. E., LeBrasseur, R. J., Kennedy, O. D. (1969). Shallow scattering layer in the subarctic Pacific Ocean: detecting by high-frequency echo sounder. Science 166 : $611-613$

Boyd, C. M. (1973). Small-scale spatial patterns of marine zooplankton examined by an electronic in situ zooplankton detecting device. Neth. J. Sea Res. 7: 103-111

Cassie, R. M. (1963). Micro-distribution of plankton. Oceanogr. mar. Biol. A. Rev. 1: 223-252

Cox, D. R., Hinkley, D. V. (1974). Theoretical statistics. Chapman and Hall, London

Cushing, D. H., Tungate, D. S. (1963). Studies on a Calanus patch. I. The identification of a Calanus patch. J. mar. biol. Ass. U.K. 43: 327-337

Fasham, J. J. R., Angel, M. V., Roe, H. S. J. (1974). An investigation of the spatial pattern of zooplankton using the Longhurst-Hardy plankton recorder. J. exp. mar. Biol. Ecol. 16: 93-112

George, D. G., Edwards, R. W. (1976). The effect of wind on the distribution of chlorophyll $a$ and crustacean zooplankton in a shallow eutrophic reservoir. J. appl. Ecol. 13: $667-690$

Greenblatt, P. R., Shulenberger, E., Wormuth, J. H. (1982). Sinall-scale distributions of zooplankton biomass. Deep Sea Res. 29: 443-457

Hamner, W. M. (1988). Behavior of plankton and patch formation in pelagic ecosystems. Bull. mar. Sci. 43: 752-757

Hamner, W. M., Carleton, J. H. (1979). Copepod swarms: attributes and role in coral reef ecosystems. Limnol. Oceanogr. 24: $1-14$

Hardy, A. C. (1936). Observation on the uneven distribution of oceanic plankton 'Discovery' Rep. 11: 511-538

Kawamura, A. (1982). Food habits and prey distributions of three rorqual species in the North Pacific Ocean. Sci. Rep. Whales Res. Inst. 34: 59-91

Kawamura, A., Hirano, K. (1985). The spatial scale of surface swarms of Calanus plumchrus Marukawa observed from consecutive plankton net catches in the northeastern North Pacific. Bull. mar. Sci. 37: 626-633

Koike, I. (in press). Preliminary report of the Hakuho Maru 
cruise KH-91-3. Ocean Research Institute, University of Tokyo

Lasker, R. (1975). Field criteria for survival of anchovy larvae: the relation between inshore chlorophyll maximum layers and successful first feeding. Fish. Bull. U.S. 73: 453-462

LeBrasseur, R. J., Barraclough, W. E., Kennedy, O. D., Parsons, T R. (1969). Production studies in the strait of Georgia. Part III. Observations on the food of larval and juvenile fish in the Fraser River plume, February to May, 1967. J. exp. mar. Biol. Ecol. 3: 39-50

Longhurst, A. R., Reith, A. D., Bower, R. E., Seibert, D. L. R. (1966). A new systern for the collection of multiple serial plankton samples. Deep Sea Res. 13: 213-222

Mackas, D. L., Boyd, C. M. (1979). Spectral analysis of zooplankton spatial heterogeneity. Science 204: 62-64

Mackas, D. L., Denman, K. L., Abbott, M. R. (1985). Plankton patchiness: biology in the physical vernacular. Bull. mar. Sci. 37: 652-674

McCullagh, P., Nelder, J. A. (1989). Generalized linear models, 2nd edn. Chapman and Hall, London

Morishita, M. (1959). Measuring of dispersion of individuals

This article was presented by K. Furuya, Tsu, Japan and analysis of the distributional patterns. Mem. Fac. Sci, Kyushu Univ. E2: 215-235

Mullin, M. M., Williams, W T. (1983). Spatial/temporal scales of zooplanktonic assemblages in three areas of the North Pacific - a further analysis. Deep Sea Res. 30: 569-574

Paffenhöfer, G.-A., Sherman, B. K., Lee, T. N. (1981). Summer upwelling on the southeastern continental shelf of the USA during 1981: abundance, distribution and patch formation of zooplankton. Prog. Oceanogr. 19: 403-436

Platt, T., Denman, K. L. (1975). Spectral analysis in ecology. A. Rev. Ecol. Syst. 6: 189-210

Richardson, L. F. (1922). Weather prediction by numerical process. Cambridge Universtiy Press, London

Smith, L., Miller, C. B., Holton, R. L. (1976). Small-scale horizontal distribution of coastal copepods. J. exp. mar. Biol. Ecol. 23: 241-253

Stavn, R. H. (1971). The horizontal-vertical distribution hypothesis: Langmuir circulations and Daphnia distributions. Limnol. Oceanogr. 16: 453-466

Wiebe, P. H. (1970). Small-scale spatial distribution in oceanic zooplankton. Limnol. Oceanogr. 15: 203-215

Manuscript first received: December 8, 1992

Revised version accepted: March 23, 1993 